\title{
Science education reforms in the UK
}

\section{As children return to school at the end of the summer in the UK, planned reforms aim to increase their science and maths literacy. A comprehensive foundation in these essential subjects is necessary to ensure that the UK remains at the forefront of science and technology for decades to come.}

The UK government's planned overhaul of school education in England aims to improve educational standards in core subjects, including mathematics and science. The plan was initiated after recent surveys, including the PISA (Programme for International Student Assessment, aimed at 15 year olds; http://www.oecd.org/pisa/), showed that the UK has fallen behind dramatically in reading and maths relative to other OECD (Organisation for Economic Co-operation and Development) countries between the years 2000 and 2009.

What, then, is the state of the UK science education? Although PISA suggests that the UK is doing comparatively well in science - it is the only area in which the UK is above the average of OECD countries the Royal Society paints a different picture. In their series of 'state of the nation' reports (http://royalsociety.org/education/policy/state-ofnation/), the Royal Society points out that many children lose interest in mathematics and science during secondary school (ages 11-16), and that there are too few students doing higher science A-levels (ages 16-19) to secure sufficient uptake into undergraduate degree programs in STEM (science, technology, engineering and mathematics) subjects. Although science and mathematics are compulsory in secondary school, only $28 \%$ of students took a science A-level in England in 2008-09. Furthermore, in England, a fairly narrow limit of 3-4 A-levels for students aged 16-19 often results in students undertaking only one science subject. Thus, students can depart the school system without having gained a broader scientific education.

A shortage of qualified teachers in mathematics and science may also exacerbate the problem. At the primary level, only a small fraction of teachers have a background in science and mathematics. As pointed out by SCORE (comprising the Association for Science Education, Institute of Physics, Royal Society, Royal Society of Chemistry and Society of Biology) in their feedback to the primary curriculum draft, it is essential that funding and support is available to improve subject knowledge at this level. Rightly, they also state that the curriculum must more explicitly encourage teaching the nature and methods of science. However, this requires confident teachers. At higher levels too, despite efforts to encourage graduates to enter the profession, the Royal Society reports a chronic shortage of mathematics and science teachers (Scotland being the exception). This is particularly concerning at the A-level stage, where a high degree of subject knowledge is essential.
The current assessment system at the age of 16 (GSCEs; General Certificate of Secondary Education) may present another hurdle as 'teaching and learning for tests' (prevalent in the UK education system), and is very unlikely to inspire anyone to pursue a career in science. Education secretary Michael Gove intends a reform of the assessment system, but whether this would help the situation is unclear. The best way forward may be to scrap national exams entirely until the A-level stage, which would encourage more flexible and creative teaching. In Finland, a nation that has among the highest performing students in the world and whose school system has inspired the UK government, national testing and school ranking lists do not exist.

In parallel to increasing the number of students specializing in higher STEM education, it is important to maintain a broader perspective. Encouraging all students and the general population to have an understanding of scientific principles should be a priority if the UK wishes to stay at the forefront of science and technology. Raising the level of science education would endow citizens with the capacity to evaluate ideas from a scientific perspective and function as a buffer against pseudo-science and anti-scientific ideas. It is interesting to note that the government now suggests that the new primary school science curriculum covers evolution. Schools in the UK have remained fairly resistant to the wave of creationism that has managed to invade the education system in some states in the USA. Although a significant minority of schools in England are religious, the head of the Church of England (which represents the largest fraction of these schools), the Archbishop of Canterbury, is against teaching creationism in schools, and anti-evolution supporters do not have a strong foothold in these schools. However, the threat to a scientifically sound education may lie elsewhere. Worryingly, a few free schools (that are funded through the state but with greater independence in choosing their curriculum) formed by creationist groups have been approved by the government. Although creationism and intelligent design will not feature in science lessons, there is concern that the science taught to the students will be undermined by the extreme views of these groups.

The new National Curriculum is far from finalized and will not be implemented until 2014. In the continued process of improving the standards of education, the UK should aim to develop a strong curriculum and teaching style that encourages independent and critical thinking from an early age. 